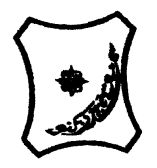

Bayero Journal of Pure and Applied Sciences, 14(1):120 - 129

Received: December, 2020

Accepted: March, 2021

ISSN 2006 - 6996

\title{
RADIO FREQUENCY IDENTIFICATION (RFID) AND DATABASE - BASED ATTENDANCE MANAGEMENT SYSTEM
}

\author{
${ }^{1}$ Ahmad, U. S., ${ }^{1}$ Bisu, A. A., ${ }^{1}$ Umar, F.A. and ${ }^{2}$ Balarabe, U. \\ ${ }^{1}$ Department of Physics/Electronics Bayero University, Kano, Nigeria. \\ ${ }^{2}$ Directorate of Examinations, Admissions and Record, Bayero University, Kano, Nigeria. \\ aabisu.elt@buk.edu.ng
}

\begin{abstract}
Effective record and management of students and staff attendance of academic and nonacademic activities/events are vital for the smooth functioning of the educational system. This is still a difficult task in most institutions, particularly in Nigeria with a large number of staff and students attending different academic and non-academic functions. This is even more difficult to manage when the traditional method of paper and pen is used to record attendance, prone to errors, and in most cases lack integrity due to manual handling of the record. Electronics and Information Communications Technologies (ICT) can be deployed to help mitigate these problems and improve reliability, ease, speed, efficiency, effectiveness, and integrity of recording and managing attendance. In this work, we used Radio Frequency Identification (RFID) and database management to provide an alternative solution that addresses issues of objects (humans and non-humans) authentication, authorization, and record management with high accuracy, reliability, and integrity using RFID-Arduino technology. The system works by reading staff's and/or student's details stored in a unique $R F$ tag wirelessly through the $R F$ reader and then matched and stored the record in the system's database. Attendance marking was achieved by matching the scanned ID with the database record. The system was successfully implemented and tested with 10 students and staff participants with the feature of exporting the records into excel format for statistical analysis and performance evaluation.
\end{abstract}

Keywords- Attendance, RFID, Electronics, RF, Database, Identity, Communications, and System.

INTRODUCTION

The rapid increase of students and staff particularly in the higher education system in Nigeria posed a challenge in the way staff and student's information is recorded, managed, stored, and retrieved for analysis and evaluation. Attendance record and monitoring could be a difficult task in an institution of higher learning with a large number of staff and students attending different academic and non-academic functions. It is often a daunting task using a traditional method of pen and paper and more susceptible to error for data mining. Moreover, Pen-paper based system is associated with many drawbacks such as distraction to the class while passing attendance sheets, and waste of time during roll-call and verification (Isinkaye et al., 2020). It's also be easily manipulated or tempered by the students. Handling and statistical analysis of the information by staff could be monotonous and time-consuming (Aiswarya et al., 2019). Thus, to provide a solution to these problems different autonomous systems were proposed by researchers and hobbies (Hoo and Ibrahim, 2019). In(Clyde et al., 2020; Munigala et al., 2019) facial recognition methods were used to automate the attendance system using a digital camera to capture an image of a person. Using the Eigenfaces technique, data obtained were analyzed and retained in the database for authentication later. Moreover, (Kadry and Smaili, 2010) proposed and implemented a wireless attendance management system for employee-based environment. This system was designed tocapture the iris pattern of individuals and analyse it using Daugman's algorithm. In spite of non-intrusive nature of these systems, their usefulness are limited with epileptic power supply and often expensive to implement especially in Nigerian higher institution with limited budgets.

However, several implementations of autonomous attendance systems used Radio Frequency Identification (RFID) system as an alternative low-cost implementation (Alghamdi, 2019)(Eridani and Widianto, 2015).RFID technology is a versatile technology used for applications infacets of human endeavors 
BAJOPAS Volume 14 Number 1,June, 2021

It's a contactless wireless electronic system that communicates information wirelessly in a range of frequencies using small circuitry with low power demand (Agrawal and Biswas, 2014). A combination of RFID-biometric/GSM was deployed in (Chatratiet al., 2013), (Konatham et al., 2016), (Ansari et al., 2011), to enhance and upgrade the validity of the autonomous attendance record but very few uses RFIDArduino based technology. Arbain et al.(2014)present a web-based laboratory attendance system by integrating RFID-Arduino technology to record and manage the student's record. In (Morerwaet al., 2020), examination hall access control was designed and implemented using RFID-Arduino technology to provide access control in academics domain. In this work, we present the design and implementation of an RFID-based attendance management system using the Arduino Uno module attached to a personal computer to facilitate the digitization and management of the student's attendance record. The main objective is to design a low-cost, power-efficient, and highly robust automatic attendance system suitable for areas with an intermittent power supply like Nigeria.

\section{MATERIALS AND METHODS}

The electronic attendance (e-Attendance) system in this work is based on Radio Frequency Identification (RFID) systems and techniques which consists of a tag and a reader that communicate wirelessly using electromagnetic (EM) wave (Hoo and Ibrahim, 2019). A typical RF tag or transponder is made up of portable carrier embedding a microchip that stores a data, an antenna through which the tag sends and receive data. The RF reader or interrogator communicates to the tag through the antenna. A reader may have a dual function antenna or a separate type for sending and receiving the EM wave (Wahab et al., 2010). Tag is broadly classified into two passive and active with the main difference on the activation power requirement. An Active tag must embody an internal battery to operate while a passive tag acquires its power through electromagnetic induction with the reader (Ansari et al., 2011). RFID systems operate in a range of frequencies (Table 1) which determines the read range of the reader and its throughput. The RFID system used in this work consists of an RF reader and a passive tag each of high-frequency range (13.56 $\mathrm{MHz}$ capacity). The complete system comprises of RFID system as the attendance system, Arduino Uno containing microcontroller unit forming the attendance database, and a personal computer serving as the user interface

Table 1: RFID Operation Frequencies and their read rang (Ansari et al., 2011).

\begin{tabular}{cccc}
\hline Band Name & Frequency Range & Use Capacity & Read Range \\
\hline Low Frequency (LF) & $30 \mathrm{kHz}-300 \mathrm{kHz}$ & $125 \mathrm{kHz}$ & up to 0.33 metre \\
High Frequency (HF) & $3 \mathrm{MHz}-30 \mathrm{MHz}$ & $13.56 \mathrm{MHz}$ & Up to 1 metre \\
Very High Frequency (VHF) & $30 \mathrm{MHz}-300 \mathrm{MHz}$ & Not used for RFID & Not applicable \\
Ultra-High Frequency (UHF) & $300 \mathrm{MHz}-3 \mathrm{GHz}$ & $866 \mathrm{MHz}, 915 \mathrm{MHz}$ & From 3 to 6 metre \\
\hline
\end{tabular}

Materials used for the design and implementation of the system proposed include hardware and software. Cost-on-the-shelfterminals (COST) hardware that is commercially available with the following technical specifications were used:

1. RF reader: Model RFID-RC522, Operating Frequency $13.56 \mathrm{MHz}$, Power Rating $0.86 \mathrm{~mW}$, Dimension of $60 \times 39$ $\mathrm{mm}$, Read Range greater than $50 \mathrm{~mm}$, Max Data Transfer Rate 10Mbit/s.

2. Smart Tag (RFID/NFC Classic): Frequency $13.56 \mathrm{MHz}$, Dimension $85 \times$ $54 \mathrm{~mm}$, Non-volatile EEPROM storage of 1 Kilobyte ( 8 Kilobit), 4 Byte unique identifier burned into the chip.

3. USB Arduino Uno board: Model ATmega328P, 32KB memory, 2KB SRAM and 1KB EEPROM.

4. Data Logger(Real Time Clock)/Memory Card Reader Circuit: RTC model DS1307 and SD interface compatibles with FAT16/FAT13 format card

Figure 1 shows the hardware components of the design and developed e-attendance system. Arduino compiler and MySQL database were used to implement the programme software. The implementation procedure was described in the following sub-section. 


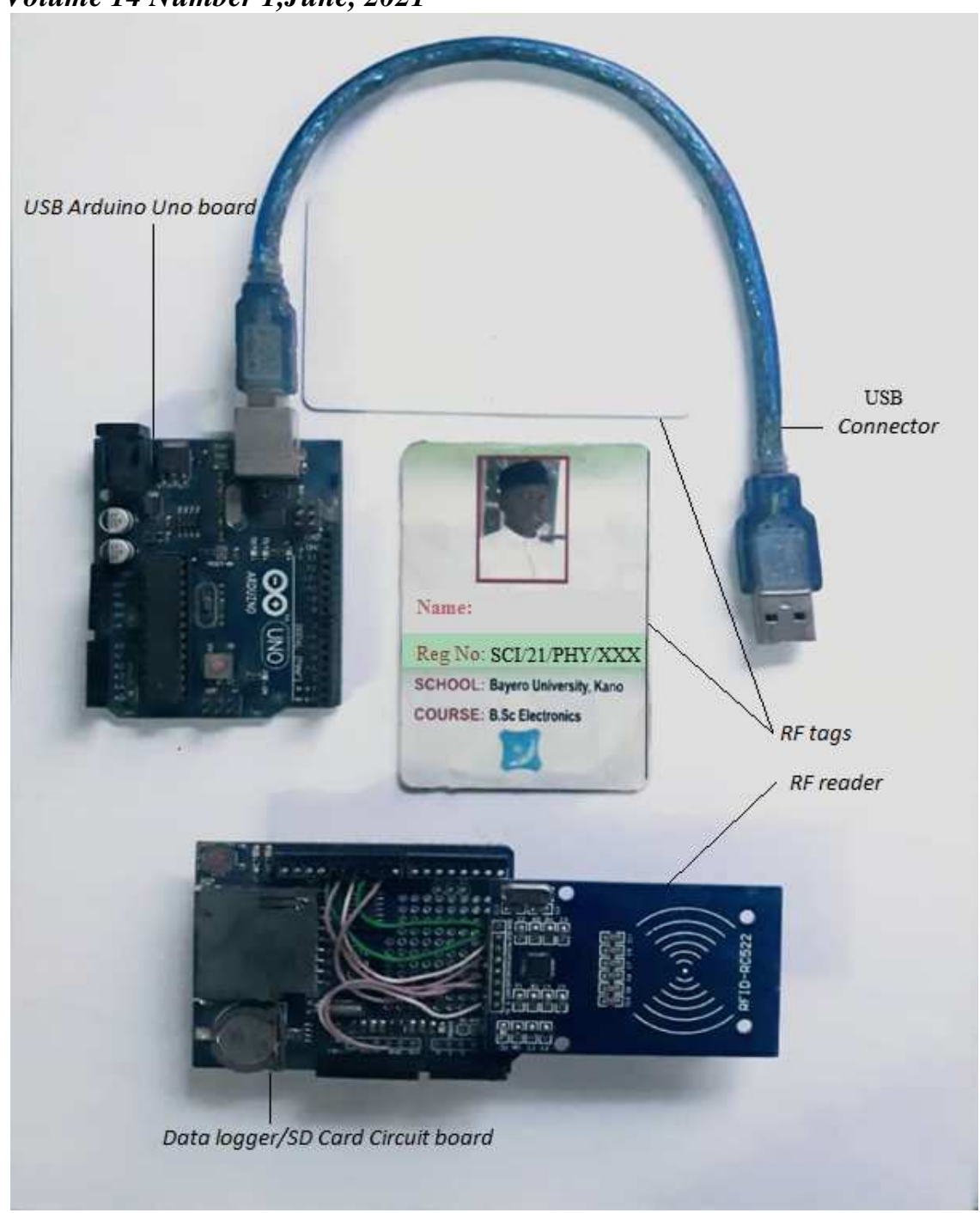

Figure 1.0: Hardware component of the system

\section{System Design and Operation}

The initial phase of the process was an enrollment of user's details by matching them with the unique identifier (UID) number of the MIFARE classic card (RF tag).The user's information such as registration number and name is provided during the registration and at the same time, UID of the MIFARE classic card is retrieved upon placing the tag within the RF reader range. This information is linked and stored in the system database as a template for future verification. During authentication, the UID of the tag is read again and compare with the existing record in the database to validate a user. After successful matching, attendance is marked against the name of the synced UID in the database. Figure 2.0 shows the architecture of the attendance management system.

\section{Database Implementation}

The attendance management system database was implemented using MySQL database (XAMPP) which formed into a profile and attendance table. The profile table contains the record of the student's profile and the UID for the RFID card assigned to each student. When a person scans his card, the system will capture his UID number and compare it with the record in the database profile table. If the record was found, his information will be keyed in the attendance table with the following details: UID number, name, date of the attendance, and time in. During sign-out, upon scanning the card again time out will be logged, and the system will generate the time interval keyed in the database. This record can be kept in an internal/external memory or printed for documentation purposes. 


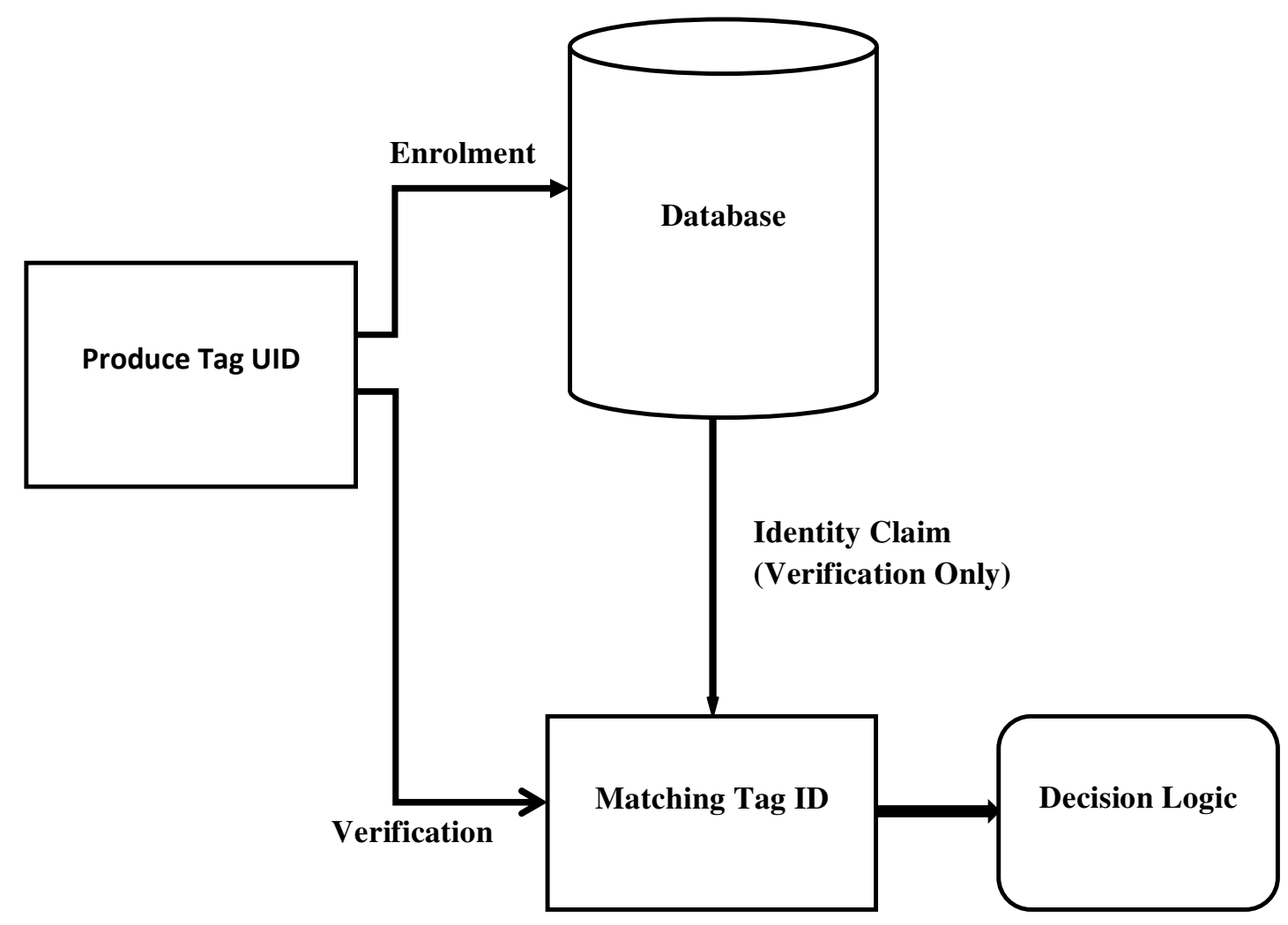

Figure 2: Enrolment and Identification Process

\section{RESULTS AND DISCUSSION}

The e-attendance system was designed and developed using RFID technology described in the previous sections. Successful implementation and testing of the designed system were also carried out using three (3) participants registered in the system's database and matching UID tags. Figure 3 shows the enrolment window for registering new users in the system's database. The enrolment process started with the system administrator assigning a unique staff no, and UID number matching the name of staff that would be allowed administrative control of the record. After successful administrative login, each student participant was registered using their names, registration numbers, and uniquely assigned tags. The system was then tested unit-by-unit as well as the combined modules making the embedded system as shown in Table 2. The system's performance was analyzed and evaluated based on the system's components functionality response, accurate and erroneous enrolments of the registered student participants' smart ID card. The system performance and accuracy were found to be efficient and effective with the number of enrolments passed with excellent performance on every test as shown in the Table 2 . 
BAJOPAS Volume 14 Number 1,June, 2021

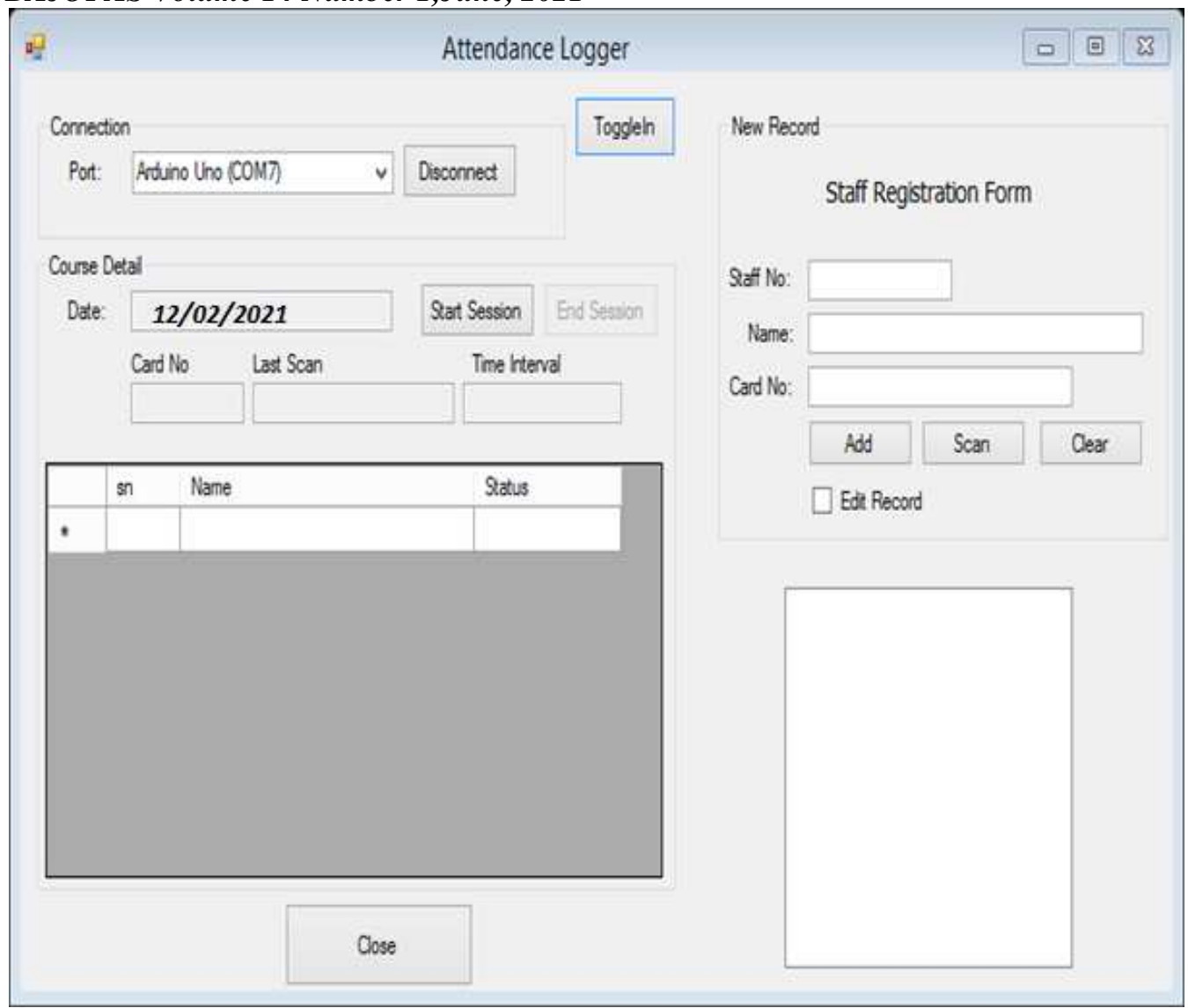

Figure 3: Enrolment window

Table 2:Units and Integrated module test

\begin{tabular}{|c|c|c|c|}
\hline S/No & Module & Test Description & Status \\
\hline 1 & Staff Register & $\begin{array}{c}\text { This module registers new staff to the } \\
\text { database by registering their profile and } \\
\text { card id }\end{array}$ & Passed \\
\hline 2 & Profile Edit & $\begin{array}{l}\text { This module allows staff profile to be recall } \\
\text { and edited }\end{array}$ & Passed \\
\hline 3 & Serial Port Connection & $\begin{array}{l}\text { The application is capable of connecting to } \\
\text { the Arduino board via serial connection }\end{array}$ & Passed \\
\hline 4 & Attendance Login & $\begin{array}{l}\text { The application accepts staff id from his } \\
\text { card, verifies it, displays the staff name, } \\
\text { and captured the time that staff login }\end{array}$ & Passed \\
\hline 5 & Attendance Logout & $\begin{array}{l}\text { The application accepts staff id from his } \\
\text { card, verifies it, displays the staff name, } \\
\text { and captured the time he logout and the } \\
\text { duration of his stay }\end{array}$ & Passed \\
\hline 6 & $\begin{array}{l}\text { Integrated units: } \\
\text { Registration, Profile Edit, } \\
\text { and Attendance. }\end{array}$ & $\begin{array}{l}\text { These modules were simulated and tested } \\
\text { for the flow of information between them. }\end{array}$ & passed \\
\hline
\end{tabular}

One of the robust features of this system was that enrolment and authentication can go simultaneously. The designed and implemented e-Attendance system always initialize with a current date memory automatically and appears ready for an RF tag to be scan before any activity starts. When a tag is placed within the RF reader's range, the e-Attendance system retrieved the unique card information and search for a match within the database for storing the details in external/internal memory in the form of an attendance list. When the matching record is found, the user's name and attendance status are displayed and recorded as either sign-in or out. 
BAJOPAS Volume 14 Number 1,June, 2021

The e-Attendance system returned an error message 'unregistered tag' when unregistered students' smart ID cards were scanned and moved to the enrolment phase through the toggle button. Figures 4.0 and 5.0 show sample outputs of the e-Attendance management system and Figure 6.0 presents the e-
Attendance database record. The system was powered through the 5V USB connection from the host PC. Therefore, the power supply relies on the battery capacity of the PC, and a minimum of two hours charged capacity sustained the attendance system throughout a day during the test experiment.

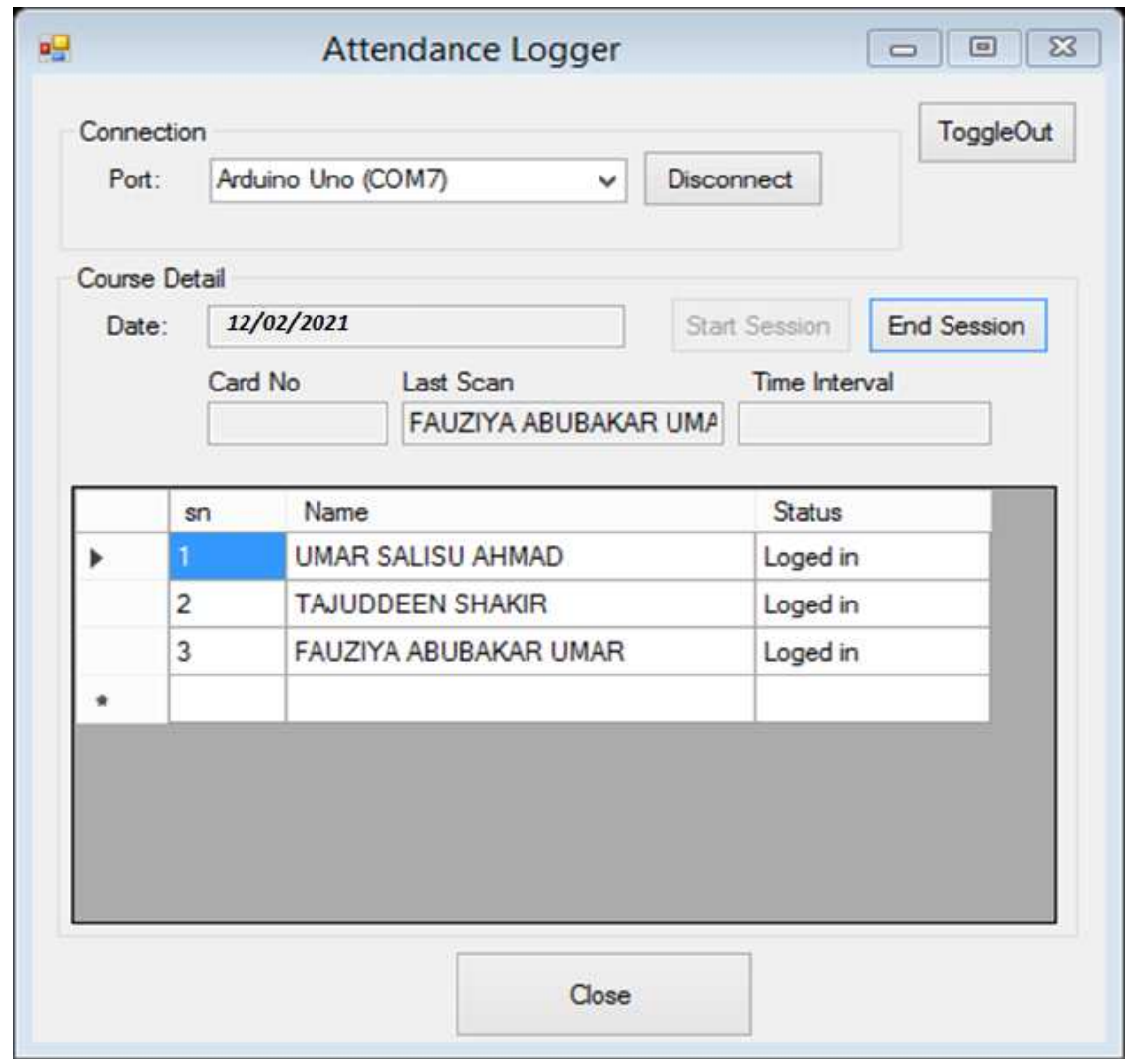

Figure 4: Login authentication window

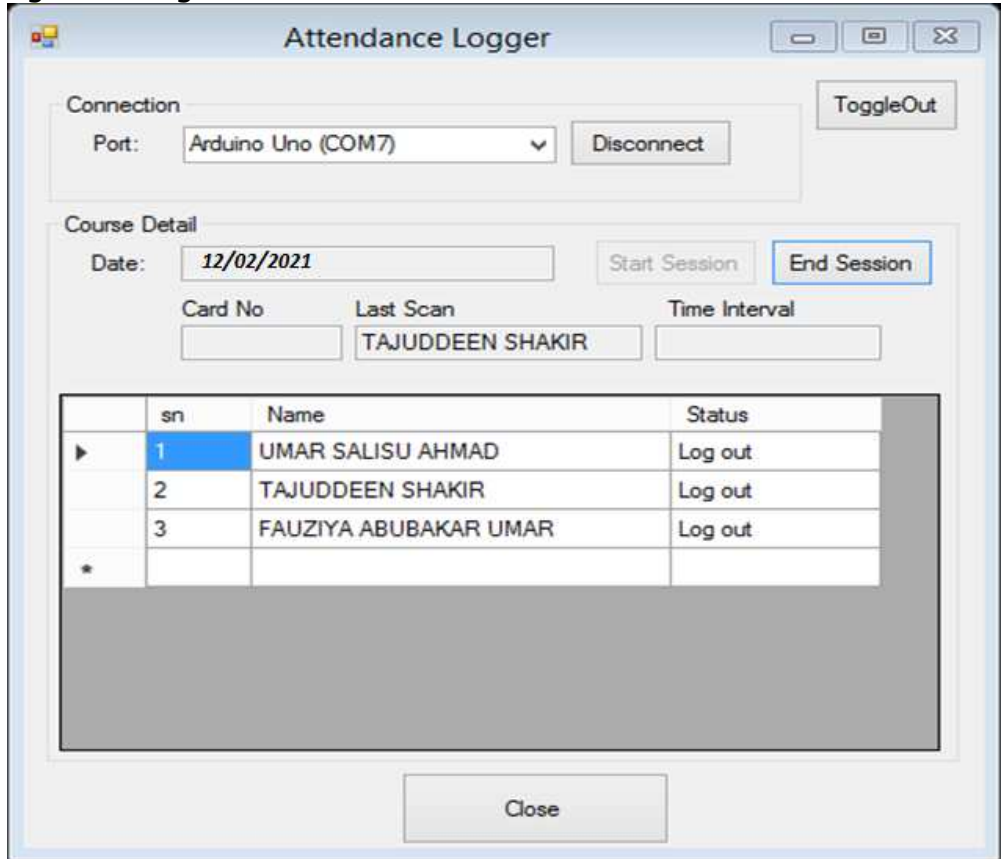

Figure 5: Logout authentication window 
BAJOPAS Volume 14 Number 1,June, 2021

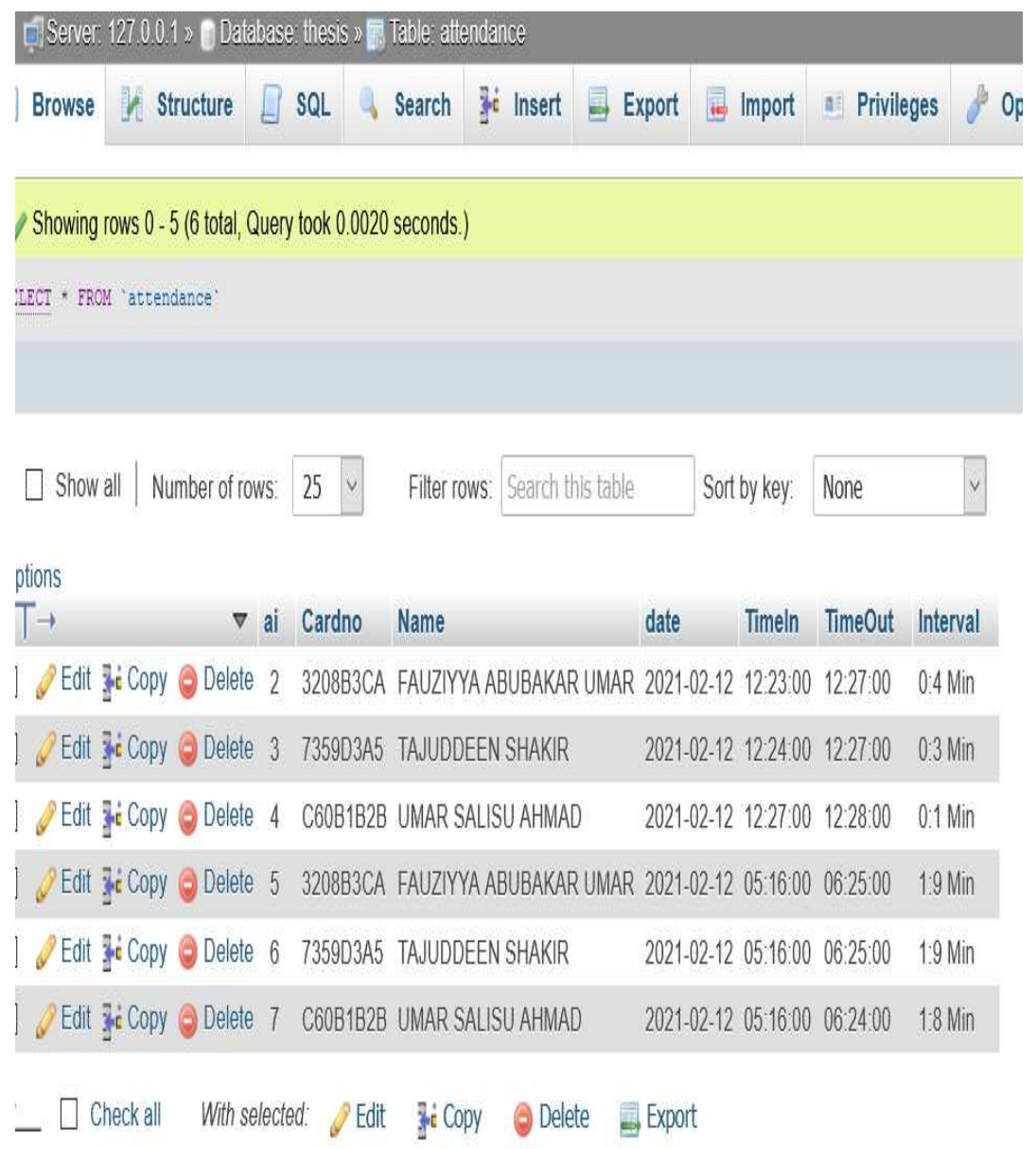

Figure 6: Attendance database record

\section{CONCLUSION}

This work presents a design, development, implementation, and testing of a low-cost, lowpower, fast and efficient e-Attendance management system based on RFID technology. This is aimed at mitigating the inefficiencies and problems associated with the traditional pen and paper attendance method. The built-up system was successfully tested with three student participants that have assigned a unique smart ID cards which was validated to work efficiently. The results showed the effectiveness and excellent performance of the system in

\section{REFERENCES}

Agrawal, T., \& Biswas, P. K. (2014). Energy consumption evaluation framework for passive RFID tag anti-collision algorithms. International Journal of Radio Frequency Identification Technology and Applications, 4(3), 229243.

https://doi.org/10.1504/IJRFITA.2014.0 63903 managing attendance digitally in a real educational environment in a well-automated and reliable record management. This guarantees efficient student/staff monitoring, record tracking and prevent data loss compared to the traditional manual attendance system. In addition, the results showed the e-Attendance system help to ease the administrative burden in monitoring and managing student record as the database record could be used to generate and export students' record in excel format for performance evaluation and analysis.

Aiswarya, S., Josmin, P., Minnu, C., \& Linda, S. (2019). Automated attendance management system using face recognition. International Journal of Innovative Technology and Exploring Engineering, 8(12), 1377-1381. https://doi.org/10.35940/ijitee.L3931.10 81219 
BAJOPAS Volume 14 Number 1,June, 2021

Alghamdi, S. (2019). Monitoring Student Attendance Using a Smart System At Taif University. International Journal of Computer Science and Information Technology, 11(01), 107-115. https://doi.org/10.5121/ijcsit.2019.1110 8

Ansari, A. N., Navada, A., Agarwal, S., Patil, S., \& Sonkamble, B. A. (2011). Automation of attendance system using RFID, biometrics, GSM modem with .Net framework. 2011 International Conference on Multimedia Technology, ICMT 2011, 2976-2979. https://doi.org/10.1109/ICMT.2011.600 2032

Arbain, N., Nordin, N. F., Isa, N. M., \& Saaidin, S. (2014). LAS: Web-based laboratory attendance system by integrating RFIDARDUINO technology. 2014 2nd International Conference on Electrical, Electronics and System Engineering, ICEESE 2014, 89-94. https://doi.org/10.1109/ICEESE.2014.71 54601

Chatrati, S., Naidu, S., \& Prasad, C. R. (2013). RFID based student monitoring and attendance tracking system. 2013 4th International Conference on Computing, Communications and Networking Technologies, ICCCNT 2013, 2-6. https://doi.org/10.1109/ICCCNT.2013.6 726702

Clyde, G., Sagar, C., Tanmay, D., \& Dipti, J. (2020). Class attendance Management System using Facial Recognition. 2020 International Conference on Decision Aid Sciences and Application, DASA 2020, 02001, 228-232. https://doi.org/10.1109/DASA51403.202 0.9317104

Eridani, D., \& Widianto, E. D. (2015). Simulation of attendance application on campus based on RFID (radio frequency identifiation). Retrieved February 6, 2021, from https://www.researchgate.net/publicatio n/304416895_Simulation_of_attendance _application_on_campus_based_on_RFI D_radio_frequency_identifiation

Hoo, S. C., \& Ibrahim, H. (2019). Biometric- based attendance tracking system for education sectors: A literature survey on hardware requirements. Journal of Sensors. https://doi.org/10.1155/2019/7410478

Isinkaye, F. O., Soyemi, J., \& Arowosegbe, O. I. (2020). An Android-based Face Recognition System for Class Attendance and Malpractice Control. International Journal of Computer Science and Information Security (IJCSIS), 18(1), 79-83.

Kadry, S., \& Smaili, M. (2010). Wireless attendance management system based on iris recognition. Scientific Research and Essays, 5(12), 1428-1435.

Konatham, S., Chalasani, B. S., Kulkarni, N., \& El Taeib, T. (2016). Attendance generating system using RFID and GSM. 2016 IEEE Long Island Systems, Applications and Technology Conference, LISAT 2016, 35. https://doi.org/10.1109/LISAT.2016.749 4157

Morerwa, D. J., Owolawi, P., \& Aiyetoro, G. (2020). Examination hall access control system using Radio Frequency Identification. 2020 International Conference on Artificial Intelligence, Big Data, Computing and Data Communication Systems, ICABCD 2020 Proceedings.

https://doi.org/10.1109/icABCD49160.20 20.9183827

Munigala, S., Mirza, S., Fathima, Z., \& Maheen, Z. (2019). Automatic Attendance Management System Using Face Recognition. IJCSN-International Journal of Computer Science and Network, 8(2). Retrieved www.ijcsn.orgimpactfactor: 1.5172

Wahab, M. H. A., Mutalib, A. A., Kadir, H. A., \& Mohsin, M. F. M. (2010). Design and development of portable RFID for attendance system. Proceedings - 2010 International Conference on Information Retrieval and Knowledge Management: Exploring the Invisible World, CAMP'10, 173-178. https://doi.org/10.1109/INFRKM.2010.5 466925 
BAJOPAS Volume 14 Number 1,June, 2021

\section{Appendix: Source Code}

$\#$ include $<$ RTClib.h $>$

\#include $<$ SPI.h $>$

\#include $<$ Wire.h $>$

\#include $<$ dht.h $>$

\#include<MFRC522.h>

\#include<RFID.h>

/*Project for My Thesis

* Example sketch/program showing how to read data from a PICC to serial.

* This is a MFRC522 library example; for further details and other examples see: https://github.com/miguelbalboa/rfid

* Example sketch/program showing how to read data from a PICC (that is: a RFID Tag or Card) using a MFRC522 based RFID

* Typical pin layout used:

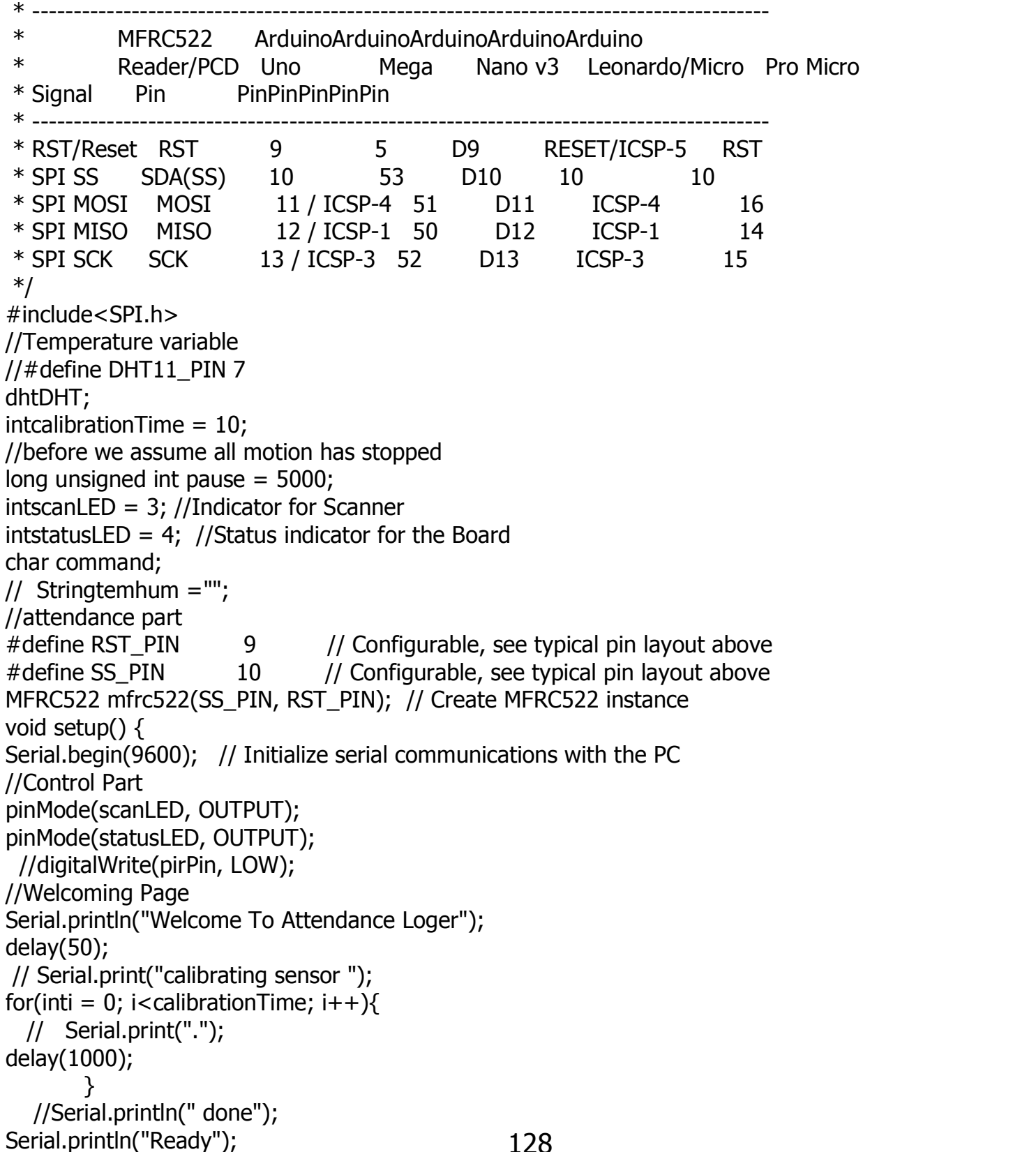


BAJOPAS Volume 14 Number 1,June, 2021

delay(50);

digitalWrite(statusLED , HIGH);

//Attendance part

while (!Serial); // Do nothing if no serial port is opened (added for Arduinos based on ATMEGA32U4)

SPI.begin(); // Init SPI bus

mfrc522.PCD_Init(); // Init MFRC522

\}

void $\operatorname{loop}()\{$

// Look for new cards

if ( ! mfrc522.PICC_IsNewCardPresent()) \{

return;

\}

// Select one of the cards

if ( ! mfrc522.PICC_ReadCardSerial()) \{

return;

\}

// Dump debug info about the card; PICC_HaltA() is automatically called

//mfrc522.PICC_DumpToSerial(\&(mfrc522.uid));

String rfidUid = "';

for (byte $\mathrm{i}=0$; $\mathrm{i}<$ mfrc522. uid.size; $\mathrm{i}++$ ) \{

rfidUid += String(mfrc522.uid.uidByte[i] < 0x10 ? "0" : "');

rfidUid $+=$ String(mfrc522.uid.uidByte[i], HEX);

\}

rfidUid.toUpperCase();

digitalWrite(scanLED ,HIGH);

//Serial.print("\#S|LOG|[");

Serial.println(rfidUid);

//Serial.println("]\#");

delay(100);

digitalWrite(scanLED, LOW);

// using PLX-DAQ excel

//Serial.print("DATA,TIME,") ;Serial.printIn(rfidUid);

//delay(250);

//digitalWrite(scanLED , LOW);

//

rfidUid="'";

delay(2000);

\} 